\title{
Society Reports
}

\section{CAMBRIDGE UNIVERSITY HISTORY OF MEDIGINE SOGIETY}

The Annual General Meeting of the Society was held on 29 April in the Department of Radiotherapeutics, and was followed by a talk by Professor H. A. Harris on 'Highlights in the History of Clinical Neurology'.

The officers for the session $195^{8-9}$ are:

\author{
President Dr. R. Williamson \\ Vice-President Dr. A. J. Rook \\ Hon. Vice-Presidents Mr. H. B. Roderick (elected 1954) \\ Professor H. A. Harris (elected 1958) \\ Treasurer Dr. D. H. M. Woollam \\ Secretary Dr. A. P. Waterson \\ Other members Dr. L. C. Martin \\ Professor L. P. Pugh \\ The President of the Cambridge University \\ Medical Society (ex officio) \\ An undergraduate

\section{NORWEGIAN SOGIETY FOR THE HISTORY OF MEDICINE}

The Society held its first meeting of the year in Oslo on 6 March 1958, when Dr. Leiv Amundsen, Professor of Classical Culture and Languages in the University of Oslo, gave a lecture on 'Early Greek Medicine'.

Professor Amundsen took as his point of departure the relations between the Egyptian and the Greek schools of medicine. Whereas the magico-religious medicine of ancient Egypt never raised itself above the casuistic plane, the Greeks took the further step of formulating a more general view of the organism and its diseases, founded upon detailed and non-mystical descriptions of symptoms.

The speaker then turned to Hippocrates and gave a vivid and interesting account of the medical school of Cos. In conclusion, he made some comments on the Hippocratic Oath.

Dr. Bernhard Getz gave an account of Norwegian skeletal remains from the Stone Age. Although the available material is relatively small, it is, when studied in conjunction with other archaeological findings, sufficient to shed some light on the original inhabitants of Norway.

There were short discussions following both papers. At the next meeting of the Society the speaker will be Dr. Robin Faahraeus, Professor of Medical History at the University of Uppsala, Sweden.

BERNHARD GETZ 